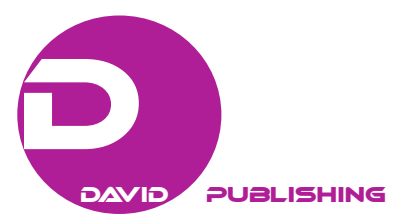

\title{
Design Thinking: Why Managers Should Care
}

\author{
Katarzyna Bachnik \\ Warsaw School of Economics, Warsaw, Poland
}

\begin{abstract}
The article focuses on a thinking and doing mode of designers, called design thinking, that might be adopted by managers in order to free organizational creativity and innovation. It is assumed that cross-disciplinary approach helps to uncover customer needs and preferences and so it can lead to better business solutions and offerings. The effectiveness of the approach is guaranteed by the fact that design innovation arises at the intersection of technological input (which guarantees feasibility of options being reworked on), business requirements (which speak for viability), and human values (which add usability and desirability component here). As such it has strategic value. The article investigates what makes design thinking a concept worth considering by managers. In order to find the answer to that research question, key building blocks of this philosophy are identified. The findings come from desk research (literature review) and observations drawn from author's job shadowing experiences in one American and two European business schools that teach design thinking. What results from the study is that design thinking is not that far from business as it may seem. If perceived as a holistic approach towards problem solving and generating innovations, it underlines links among various fields of organizational operations. It can be further concluded that adopting design thinking framework facilitates combining processes already existing within a company and taking them to a new level by enforcing customer-centric focus, by making the company rely on identifying many options and experimenting with few of them and by building understanding for early failures and for value of playing with concepts that seem unrelated to the core operations.
\end{abstract}

Keywords: design thinking, creativity, innovation, management, design, strategic management, problem solving

\section{Why Infuse Design Into Business}

Staying afloat on a market and finding sustainable competitive advantage is not easy for any company. That is one of the reasons why companies strive for innovation and build capacities to become more agile and adaptive to a dynamically changing environment (Sull, 2009). However, in their effort to become more innovative, they tend to adopt certain policies, structures, or practices that in the long term turn into innovation obstacles. In case of many organizational cultures, the quest of innovation fights with the willingness to protect the status quo and stay within a comfort zone. Resistance to change hinders many organizational twists and thinking outside the box has to be carefully bred and encouraged from the top of the organization to sustain (Lawrence, 1954).

Design thinking offers a solution to that problem. As a cross-disciplinary philosophy, it transmits some tools and frameworks well established in one domain: design, into the context of business. Success stories of

Katarzyna Bachnik, Ph.D., assistant professor, Institute of Management, Warsaw School of Economics, Warsaw, Poland.

Correspondence concerning this article should be addressed to Katarzyna Bachnik, 11/33 Wawozowa Street, 02-796 Warsaw, Poland. 
such market giants as P\&G, IBM, Suncorp, 3M, Kaiser, Apple, SAP, Intuit, and Toyota, that value this approach, prove its usefulness and effectiveness (Liedtka, King, \& Bennett, 2013). Also business schools begin to appreciate the learnings. The tangible evidence is the inclusion of more design-oriented innovation courses in their agendas and bringing designers to work with business students on real-life challenges.

\section{Core Elements of Design Thinking}

Design thinking constitutes a much broader term than simply industrial design. It escapes pure aesthetic deliberations, which define the last phase of new product development. Although decisions on how the end product would or should look like are vital for product market success (as the physical appearance appeals to customer senses and sometimes might become the key product attribute that encourages them to make the purchase), design thinking covers the whole customer experience with a product. Apart from the "look", it tries to identify who will buy a particular product, why and for what purposes, as well as in what situations or circumstances it will be consumed or used. After Brown (2008, p. 2), design thinking is "a discipline that uses the designer's sensibility and methods to match people's needs with what is technologically feasible and what a viable business strategy can convert into customer value and market opportunity". This definition not only understands successful solutions as the ones addressing people's needs, but it underlines the necessity to navigate in three dimensions. Design innovation arises at the intersection of technological input (which guarantees feasibility of options being reworked on), business requirements (which speak for viability), and human values (which add usability and desirability component here) (Leifer, 2013).

To make it work, design thinking needs to be regarded as an iterative process, where various phases mix and feed one another. The iteration speaks for a trial and error model. It is assumed that having plenty of ideas and working with plenty of ideas is a good thing. This means refraining from the desire that many companies share, to work with just one, best solution, to speed things up and jump to the commercialization of an idea. Stanford's d.school (institute of design) and IDEO support the design thinking model that encompasses five stages. The order in which it is presented in Table 1 shows the basic logic behind uncovering the customer need, though multiple sequences are allowed and even encouraged, based on the particular organizational context, the actual expertise on the customer base, and the resources at hand and time frame. Learning about particular stages proves that design thinking encompasses both thinking and doing mode: Information gathering and analytical works are followed by hands-on prototyping and testing phases, where ideas are turned into tangible products.

Liedtka and Ogilvie (2011) preferred to talk about design thinking via four basic questions, which uncover the inspiration, ideation, and implementation components of design thinking. They enlist:

- What is? to explore current reality;

- What if? to envision a new future;

- What wows? to make some choices;

- What works? to take a company into marketplace.

Although the stages are replaced with questions, the logic stays the same. The company tries to understand its environment better as it searches for market opportunities and customers problems it can address in a novel way. It tries to think of many possible options, to take what it chooses back into the market (which includes the process of generating, developing, and testing ideas) and to implement what proves best. It finds the answers being clear about its particular case, the context, the customers, and the resource limitations. Framing the 
concept with questions underlines how dynamic the process is and that moving forward requires completing some preliminary steps.

Although the end results of every stage of the design thinking process shall be specific, they are expected to be very different. Unleashing the creative potential of an organization requires different level of psychological safety and different norms of behavior (how thinking should be structured and organized) than eliminating the multitude of options and sticking with just one. Divergent and convergent thinking represent this duality of design thinking. They are in opposition to each other. While divergent thinking is perfect for idea generation and working with multiple options, when it comes to idea evaluation and implementation, convergent thinking is much more efficient and useful (Kellogg, 2012; Paulus \& Nijstad, 2003).

To better understand the value of design thinking approach to business, it is vital to reflect on its core elements - the building blocks that determine its potential to create new and sustaining solutions as well as to tackle the actual and up-to-date challenges. Although this management perspective is rooted in designers' experiences and practices, it sounds quite universal as it stresses the organizational competences and skills that lay ground for a successful and competitive enterprise in the long term. The literature review and observations drawn from author's job shadowing experiences in one American and two European business schools, that teach design thinking, allow identifying following building blocks of design thinking concept.

Table 1

Five-Stage Design Thinking Model of Stanford's d.school

\begin{tabular}{|c|c|c|c|c|c|}
\hline Stage & Empathize & Define & Ideate & Prototype & Test \\
\hline Description & $\begin{array}{l}\text { Knowing the users } \\
\text { and caring about } \\
\text { their lives: effort to } \\
\text { understand the way } \\
\text { people do things and } \\
\text { why, their physical } \\
\text { and emotional } \\
\text { needs, how they } \\
\text { think about world, } \\
\text { and what is } \\
\text { meaningful to them }\end{array}$ & $\begin{array}{l}\text { Framing the right } \\
\text { problem: making } \\
\text { sense of the } \\
\text { widespread } \\
\text { information you } \\
\text { have gathered }\end{array}$ & $\begin{array}{l}\text { Generating the } \\
\text { broadest range of } \\
\text { possibilities: } \\
\text { providing both the } \\
\text { fuel and the source } \\
\text { material for building } \\
\text { prototypes and } \\
\text { getting innovative } \\
\text { solutions into the } \\
\text { hands of the users }\end{array}$ & $\begin{array}{l}\text { Building to think } \\
\text { and testing to learn: } \\
\text { generating artifacts } \\
\text { intended to answer } \\
\text { questions that get } \\
\text { you closer to the } \\
\text { final solution }\end{array}$ & $\begin{array}{l}\text { Learning about the } \\
\text { solution and the } \\
\text { user: soliciting } \\
\text { feedback about the } \\
\text { prototypes you have } \\
\text { created, from the } \\
\text { users, and having } \\
\text { another opportunity } \\
\text { to gain empathy for } \\
\text { the people you are } \\
\text { designing for }\end{array}$ \\
\hline
\end{tabular}

Source: Retrieved from https://dschool.stanford.edu/sandbox/groups/designresources/wiki/36873/attachments/74b3d/Mode GuideBOOTCAMP2010L.pdf?sessionID=c2bb722c7c1ad51462291013c0eeb6c47f33e564.

\section{Innovation and Creativity}

Innovation and creativity lie at the center of design thinking and are among these features and attributes that identify this approach as a strategic tool. Distinctive is the assumption that innovation shall be monitored and evaluated through very business-like criteria like productivity and performance. Innovation shall have utilitarian value for enterprises and for that reason should be measured, benchmarked, and linked to business objectives.

Innovation and so design as part of the innovation process requires a mental state that combines creativity, the entrepreneurial spirit, the ability to take calculated risks, and the acceptance of some degree of social, geographical, or professional mobility. Innovation requires the skill to anticipate needs, a strict but flexible organization, and the capacity to set end dates for projects and control their costs. (Montaña \& Moll, 2012, p. 21) 
Regardless of the fact that design thinking can be structured and can have milestones, any company can take this approach and use it in various situations. Being universal means that the business context for design thinking adaptation can be broad. New product development process visualizes the relation between design and business in a natural manner. Enterprises that want to be competitive on the market and attractive to customers must develop product and service offerings that respond to the competitors' and customers' needs, experiences, and aspirations. The level of creativity and innovation can greatly change the picture as it disturbs the rules of the game and introduces new elements. Even according to standardized stage-gate model of new product development, a venue for design exists. The production, marketing, operations, and finance deliberations and uncertainties are matched with design challenges. Finding right answers to right questions may speed up the whole process and end up with optimal decisions and choices.

\section{Teamwork, Working Space, Playfulness}

Innovations are not generated in isolation. Therefore, it makes sense to figure out who, what kind of people, are innovative. The experiences of various companies prove that the myth of a sole inventor is no longer acceptable. A transition from individual perspective to teamwork seems to be greatly sustained. These are teams and task forces and project squads that are accountable for innovation and creativity. The exchange of ideas, especially among people representing various fields of expertise, is much more fruitful than individual's mental considerations, neither shared nor discussed with others. That is why brainstorming is one of the tools addressed by design thinking.

The creative potential of a company depends to a large extent on its recruitment procedures and on the proper allocation of talents to particular tasks and initiatives. It is no longer a matter of having narrowly but deeply specialized experts in one field, but of a multidisciplinary team. Just as some researchers (e.g., Hill, 2008) believed that the era of charismatic leadership is over and its place is taken by "collective genius", the analogous change addresses the innovation field. Companies that adopt design thinking feel also that organization of employees' work makes a meaning. They do invest much in considering the scopes of responsibilities of particular positions and jobs and in designing the layout of the offices. The decoration and space arrangements seem important as they allow people to develop a sense of ownership of the workplace and to create a familiar atmosphere which breeds comfort and may account for playfulness.

As design management experts put it:

Like so many things, innovation lives in a world full of contradictions. Being innovative means accepting paradoxes and being able to live with them. So the innovative organization must be simultaneously centralized and decentralized, global and local, make long-term plans, and be flexible in the short-term. The staff of an innovative company must be autonomous but also capable of teamwork. The structure of the innovative company must be to some extent chaotic, but directed towards shared objectives. The structure of the design sector, with its wide range of freelance professionals, allows for flexible organization and the combination of internal and external teams. (Montaña \& Moll, 2012, p. 21)

\section{Learning, Experimentation, Prototyping, Iteration, and Failure}

Design thinking rests upon experimentation and testing. It is an iterative process of searching for options, analyzing them, evaluating, testing though building prototypes, and handling them over to potential customers for feedback, working with the feedback, and improving and modifying the concept, before one solution is chosen and translated into a viable end result (like product). The prototyping phase is about visualization: translating ideas beyond words or symbols into visual aids, frameworks, and things. Some of the used tools at 
the earlier stages allow visualizing thinking process. Prototyping is about creating physical items and stuff, in order to test assumptions, experience the product, and get new insights what works and what does not work. This stage is tough in business setting as it rests upon abilities that are not developed and honed in business schools.

Learning is a great part of innovation process. As such it is worth studying and exploring. Beckman and Barry's research (2007), based on the Kolb's learning cycles, shows that there are four main learning styles, which determine people's preferences on the specific tasks, working modes, scope of information search, and action-versus interrelations orientation. They are distinct though the emphasis that is put on:

- reflective observation or active experimentation;

- abstract conceptualization or concrete experience.

The four learning styles include: assimilating (good at understanding a wide range of information and putting it in concise, logical form), converging (good at finding practical uses for ideas and theories; solving problems), diverging (good at seeing concrete situations from multiple viewpoints), and accommodating (good a learning from hands-on experience) one.

Appreciation or acceptance of failure as a learning opportunity stands here out. It is not about accepting misfortune, but about admitting that failures happen and they are tolerable as long as a company draws insights from these experiences and do not repeat the same mistakes. Some companies like the idea of failing often and quickly as they can limit the scope of unnecessary investments in projects with little or no chances of success (Brown \& Katz, 2009).

\section{Orientation Towards Customers}

Design thinking fights with a traditional problem of balancing between the aspirations of designers (to create outstanding, sophisticated, and state-of-the-art designs) and the needs of customers (linked to aesthetic values and utilitarian ones). It is very clear that customers should go first. This human-centered approach is visible in the choice of tools and techniques that focus on the profiles of the users and their experiences. Thanks to the fact that design thinkers want to be close to the users, they are able to mix the rational and intuitive thinking. Also the innovation focuses on existing and latent needs of the customers or clients.

The recognition of very strong "bargaining" power of customers is a landmark for design thinking framework, but does not end there. The big change in how industry forces are perceived and intertwined relates to the whole marketing domain. The traditional concept of a marketing mix is made up of four factors, namely, product, price, place, and promotion (the 4Ps) that the company blends to target the market. This business orientation is for the moment being replaced by a customer's point of view. The 4Ps are evolving into 4Cs: (respectively) customer value, cost, convenience, and communication (Kotler, Kartajaya, \& Setiawan, 2010). Even though all companies may not adopt it, it highlights a certain trend, which has lots to do with the empowerment of stakeholders (in relation to enterprises).

\section{Tools and Techniques of Design Thinking}

What seems to be common for design and management is the existence of limitations and constraints. Some say that though this concept is well understood and handled by managers, designers seem to neglect it. Fully occupied by the creation process, they sometimes forget about the functional purpose of their task or of the end user of the creation output (Vossoughi \& Alviani, 2012). Others assume the opposite: The creative 
value of designers stems from the fact that they enter a constrained environment and need to tackle a problem. Faced with something that seems impossible to do, they are forced to think outside the box and in a different manner than anybody else before them (Dunne \& Martin, 2006). The differences in thinking and doing modes make designers, managers, and marketers to pick different tools and methods of dealing with ambiguity, option generation, solution picking, and problem solving. The described below examples are of techniques that originate in design and have been developed for business purposes successfully.

As design is part of the business, it needs to be effective and executable. On one hand, it needs to be appropriate to the identity and capabilities of the organization that owns it. On the other, it must convey to the person, using the designed item, what the item does, and why it is of value. The latter perspective is vital as much of designers' success depends on perceptions and expectations of their target audience. If designers can read those perceptions and aspire designed products to those expectations, the chances of consumers recognizing, valuing, and buying are higher.

Storytelling should definitely constitute a solid ground for common understanding. It is one of the basic tools for designers used to collect the necessary information, analyze the insights, figure out the options, and choose the best one (usually, if not always, after a series of test-and-trial efforts). Marketers very often use stories to build brand awareness and recognition, to build links between the brand and values cherished by the target customers, to make their marketing messages more convincing and memorable. Research shows that managers fail in this field (Liedtka, 2010). Although most big companies declared having aspirational mission statements, most of their managers did not believe that these declarations had anything to do with the reality. In other words, it was unlikely that those aspirations would be fulfilled.

In the learning process and in the innovation process, it is vital to draw conclusions from the undertakings and end results of the implemented projects. Stories describe events and contain the implicit rules that govern people's lives, they also carry emotional component that might play the role of a strong motivation. However, these are not the success stories but failure stories that matter the most. They seem to be more powerful and remembered for a longer period of time. As designers share them a lot, especially though the experimentation and testing phases, managers and marketers take the opposite approach, trying to neglect or diminish the meaning of unsuccessful initiatives. Some of them even try to hide failures, as they fear it will speak against their competences and may harm the reputation, operations and financial standing of the enterprises they run. Harvard Business Review has devoted one of their special issues (April 2011) to failures trying to make a visible point here.

Although the methods of extracting, analyzing, and processing information used by designers and managers differ a lot, their focus on data is shared. Much of the design process goes down to data searching in order to make the ideas concrete, validate assumptions, and test prototypes. It is however also true that the line between analytical and intuitive thinking in case of designers becomes very often blurred. So the analytical rigor, number crunching, and quantitative approach can be adopted from the managers then.

Observation (and ethnography), customer journey map, and mind mapping are among methods that allow design thinking to flourish. These tools can help overcome traditional problems with design process to create more usable and innovative designs.

\section{Observation}

This tool seems intuitive and straightforward, but is undeniably valuable. Observation involves watching 
people in their natural activities and usual context of living and working. It allows taking the perspective of the customer: to view what users actually do (and not what they say they do), which offers an opportunity to uncover previously undetected or diminished needs and expectations, patterns of behavior, and intrapersonal dynamics. Adding interviewing to observation leads to ethnography, understood as "the study of people in their natural settings; a descriptive account of social life and culture in a defined social system, based on qualitative methods" (Martin \& Hanington, 2012, p. 60). This collection of research methods digs into the behavioral trends and cultural determinants. It allows not only to get new insights but also to verify taken-for-granted assumptions, to break the biases, and to connect with prospective customers. Ethnography is based on a comprehensive and empathic understanding of the users and their lives.

\section{Customer Journey Map}

This method helps documenting and visualizing the experiences that customers have as they use a product or service. Though their responses as users, companies are able to access and analyze the interacting factors that form a customer experience. As it can be used with various personas and enables developing more consistent and predictable customer experience, companies can draw vital insights and, in effect, reduce number of dissatisfied customers. In order to build viable and effective customer journey map, it is needed to ask sets of four types of questions:

- Activities: What is the customer doing at each stage? What actions are they taking to move themselves on to the next stage?

- Motivations: Why is the customer motivated to keep going to the next stage? What emotions are they feeling? Why do they care?

- Questions: What are the uncertainties, jargon, or other issues preventing the customer from moving to the next stage?

- Barriers: What structural, process, cost, implementation, or other barriers stand in the way of moving on to the next stage (Kellogg, 2012; Liedtka \& Ogilvie, 2011)?

\section{Mind Mapping}

This more visual tool allows showing affinities and connections among considered options, factors, and elements. It visualizes links and associations among ideas, things, and people. It builds upon relationships and recollections people have in their memory in order to uncover the whole picture and create a better understanding of a situation. Mind mapping may recall brainstorming, but even though there is a grain of creative chaos (while building the map), much greater organization of thoughts is needed. Mind mapping is especially useful in evolving and dynamic contexts, when enterprises deal with factors that they can not control and that change quickly and where the relationships between the variables at stake stay unclear. A simple visualization of a map allows to summarize and test assumptions, make and break connections, and consider alternatives. It reflects the fact that humans think in a rather non-linear way and so they tend to rely on different ways of organizing and prioritizing information (Martin \& Hanington, 2012; Liedtka \& Ogilvie, 2011, p. 81).

\section{Conclusions}

As Liedtka and Ogilvie (2011, p. 3) simply stated: "Every manager needs design. You can not grow business without it". If this paper considers great market success of Apple, then it stands out that the designers have a vital role to play in the quality of interrelationships among all parties working on the creation, alteration, 
and launching of new products and services. It is precisely this role that gives design its strategic significance in the modern company. However, the role of design does not have to be limited only to the new product development processes. Because of the innovation and creative capacity of design thinking, this approach can be adopted by organizations in order to tackle diverse problems and challenges, far outreaching pure product-related decisions.

Following the assumption that design thinking is driven by the desire to solve problems though generating innovations, it can be concluded that this framework can-potentially-drive business value. Innovations speak for value and as such companies cherish them. Design thinking relies heavily on observing users and their physical environment, on interacting with them and letting them play with prototypes in order to get the chance to include the feedback back into the design to make it better. This combination of empathy for people and continuous search for insights allows for innovation spur. As a result, the innovative and creative power of design thinking may attract enterprises.

Adopting design thinking framework in business context may not be as hard as it may seem. If perceived as a holistic approach towards problem solving and generating innovations, it underlines links among various fields of organizational operations. It can be further concluded that adopting design thinking framework facilitates combining processes already existing within a company and taking them to a new level by enforcing customer-centric focus, by making the company rely on identifying many options and experimenting with few of them, and by building understanding for early failures and for value of playing with concepts that seem unrelated to the core operations. Instead of undergoing massive turnaround, the concept tries to build upon the strengths of the organization and set a new tone for how certain processes are planned and controlled. These qualities are enough to make the concept worth considering.

The paper tries to deliver a fundamental recognition of the value of design thinking in business context, but further studies are needed to identify how this process can be implemented within company's structure and culture and to verify what types of organizations are the best suited to try this approach in order to get the most of its benefits.

\section{References}

Beckman, S. L., \& Barry, M. (2007). Innovation as a learning process: Embedding design thinking. California Management Review, 50(1), 25-56.

Brown, T. (2008). Design thinking. Harvard Business Review, 86(6), 84-92.

Brown, T., \& Katz, B. (2009). Change by design: How design thinking transforms organizations and inspires innovation. New York: Harper Business.

d.school (Institute of Design), Stanford, USA. An introduction to design thinking. Process guide. Retrieved from https://dschool.stanford.edu/sandbox/groups/designresources/wiki/36873/attachments/74b3d/ModeGuideBOOTCAMP2010L pdf?sessionID=c2bb722c7c1ad51462291013c0eeb6c47f33e564

Dunne, D., \& Martin, R. (2006). Design thinking and how it will change management education. Academy of Management Learning \& Education, 5(4), 512-523.

Hill, L. A. (2008). Where will we find tomorrow's leaders? Harvard Business Review, 86(1), 123-129.

Kellogg, C. (2012). Presentations on design thinking (MBA course, Haas School of Business, Berkeley, USA).

Kotler, P., Kartajaya, K., \& Setiawan, I. (2010). Marketing 3.0. Warsaw: MTBiznes.

Lawrence, P. (1954). How to deal with resistance to change. Harvard Business Review, 32, 49-57.

Leifer, L. (2013). Presentation during creativity \& innovation seminar. Retrieved from http://dschool.stanford.edu/our-point-of-view/\#design-thinking

Liedtka, J. (2010). Business strategy and design: Can this marriage be saved? Design Management Review, 21(2), 6-11. 
Liedtka, J., \& Ogilvie, T. (2011). Designing for growth. New York: Columbia University Press.

Liedtka, J., King, A., \& Bennett, K. (2013). Solving problems with design thinking. 10 stories of what works. New York: Columbia Business School Publishing.

Martin, B., \& Hanington, B. (2012). Universal methods of design: 100 ways to research complex problems, develop innovative ideas and design effective solutions. Berverly: Rockport Publishers.

Montaña, J., \& Moll, I. (2012). Design management manual (ESADE Business School, Barcelona, Spain).

Paulus, P. B., \& Nijstad, B. A. (2003). Group creativity. Innovation through collaboration. New York: Oxford University Press.

Sull, D. (2009). How to thrive in turbulent markets. Harvard Business Review, 87(2), 78-88.

Vossoughi, S., \& Alviani, C. (2012). Design education: A return to basics. Design Management Review, 23(4), 56-61. 